\title{
Mobility Management Challenges and Solutions in Mobile Cloud Computing System for Next Generation Networks
}

\author{
L. Pallavi ${ }^{1}$, B. Thirumala Rao ${ }^{3}$ \\ Department of CSE \\ Koneru Lakshmaiah Education Foundation \\ Vaddeswaram, India
}

\author{
A. Jagan ${ }^{2}$ \\ Department of CSE \\ B V Raju Institute of Technology \\ Narsapur, India
}

\begin{abstract}
As of late, there is a dynamic improvement in the field of mobile computing, and mobile cloud computing (MCC) has been familiar with a potential development for portable administrations. Likewise, the mobile phones and their applications have high framework in the administration at any point and grow more rapidly. Again, MCC is depended upon to deliver on a very basic level increasingly inventive with multi applications. Moreover, Mobile handling incorporates versatile equipments, portable correspondence, cell programming, and right now there are various compact cloud applications. Versatility the board for supporting the area following and area based assistance is a significant issue of savvy city by giving the way to the smooth transportation of individuals and products. The mobility is valuable to contribute the development in both open and private transportation frameworks for keen urban communities. As the information is distributed computing and getting to it with cell phones all the exchanges experience the system so it is powerless against assault. For keeping the utilization of this fundamental apparatus of steady in this development world we are giving a portion of the answers for these difficulties to address in the field of MCC. In this paper, the main challenges faced by the enterprises and their corresponding solutions are discussed with the mobile cloud computing.
\end{abstract}

Keywords-Mobility management; energy consumption; network resource management; traffic management; security management

\section{INTRODUCTION}

Throughout late years, advances in the field of framework set up together handling and applications as for demand have incited a risky improvement of usage models, for instance, appropriated figuring, programming as an organization, arrange sort out, web store, and so forth [1]. As a vital application show in the hour of the Internet, Cloud Computing has transformed into a basic research subject of the intelligent and mechanical systems since 2007. Normally, appropriated processing is depicted as an extent of the organizations which are given by an Internet- based pack system. Such pack structures include a social occasion of negligible exertion servers or personal computers (PCs) [2], shifting through the various resources of the $\mathrm{PCs}$ as showed by a particular organization system, and offering ensured, strong, brisk, accommodating and direct organizations. For instance, data accumulating, getting to and figuring to clients [3]. In this time, PDAs are considered as the representatives of the distinctive mobile phones as they have been related with the Internet with the rapid creation of remote framework development. Inescapability and flexibility are two important features in the front line arrangement which gives an extent of the modified framework benefits through different framework terminals and strategies for getting to [4]. The inside development of disseminated processing is concentrating figuring, organizations, and express packages as an application to be offered like water, gas or capability to customers. Consequently, the mixture of a ubiquities adaptable framework and conveyed processing produces another enlisting mode, to be precise mobile cloud computing (mcc) [5]-[8]. In the meantime, the diverse programs reliant on bendy disseminated registering had been made and served to clients, as an example, Google Gmail, maps and navigation frameworks for cell, voice search, and some applications on an android degree, mobileme from Apple, live mesh from Microsoft, and Motoblur from Motorola.

The expanding situation towards MCC with the blast of versatile applications and the help of $\mathrm{CC}$ for various assortment of administrations for portable clients. MCC is presented as a combination of distributed computing with the portable figuring and cell phones. Be that as it may, alongside the helpfulness of this subject of portable distributed computing still research should be done on a few issues just as conceivable structures to help distributed computing on cell phones. MCC methods endeavor to concentrate on easing assets impediments in leaving innovation by utilizing distinctive systems of growth are screen increase, vitality enlargement, stockpiling expansion and application preparing. There are number of methodologies and contend that MCC handles that are expected to be the top of the line equipment, diminishes possession and upkeep cost, and lightens information wellbeing and client security of MCC [9]-[13]. The general model of MCC is given in Fig. 1.

In MCC, the past wireless based genuine enlisting, data storing and mass information taking care of have been traded to 'cloud' and subsequently the essentials of mobile phones in handling capacity and resources have been diminished, so the making, running, sending and using strategy for compact applications have been totally changed [14]. Of course, the terminals which people used to get to and get cloud 
organizations are suitable for PDAs like mobile phone, PDA, Tablet, and iPad yet not bound to settled contraptions, (for instance, PC), which reflects the ideal conditions and special objective of circulated figuring. Thus, from the two pieces of compact enrolling and circulated figuring, the adaptable conveyed processing is a mix of the two advances, an improvement of scattered, organized and thought estimations, and have extensive possibilities for application [15].

As shown is the Fig. 1, MCC can be basically isolated into distributed computing and portable processing. As the figuring and actual facts making ready tiers have been relocated to 'cloud', the ability necessity of cell phones is limited, some minimal effort cell phones or even non-advanced cellular phones can likewise accomplish transportable allotted computing by utilizing a cross-level mid-product [16]. Notwithstanding the truth that the patron in mcc is modified from desktops or settled machines to cellular phones, the fundamental concept remains dispensed computing. Flexible customers ship administration solicitations to the cloud via an internet browser or work location utility, the administration a part of cloud dispenses assets to the call for installation affiliation, while observing and figuring the factors of mcc might be completed to guarantee the qos till the affiliation is completed [17][18]. In MCC scene, an amalgamation of versatile processing and distributed computing correspondence systems makes a few complex difficulties. Albeit a portion of the difficulties, for example, consistent network, seller lock-in, versatility of the executives, security and protection are regular with portable registering and cloud computing [19]-[22]. A handoff the executives is required when a client moves starting with one remote cell then onto the next. At the point when a handoff happens inside the area of a homogeneous remote access innovation happening occasion is known as flat handoff and when this occasion happens among heterogeneous remote access arrange advances is known vertical handoff. Level handoff happens when the MNs are moving a long way from purpose of connection and go into the low flag quality territory in a homogeneous remote system. In a heterogeneous environment [23]-[25] (shown in Fig. 2), clients have a chance to get to the distinctive advances systems. A client might be profited by various system qualities which are not similar specifically. MN portability is upheld by vertical handoff as the correspondence innovation and access supporting foundation change. At some point vertical handoff happens because of client's comfort as opposed to inaccessibility of association. The handoff procedure turns out to be progressively intricate in such a domain contrasted with the homogeneous one.

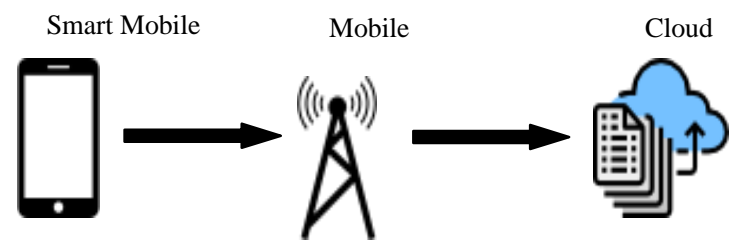

Fig. 1. Generic model of MCC.

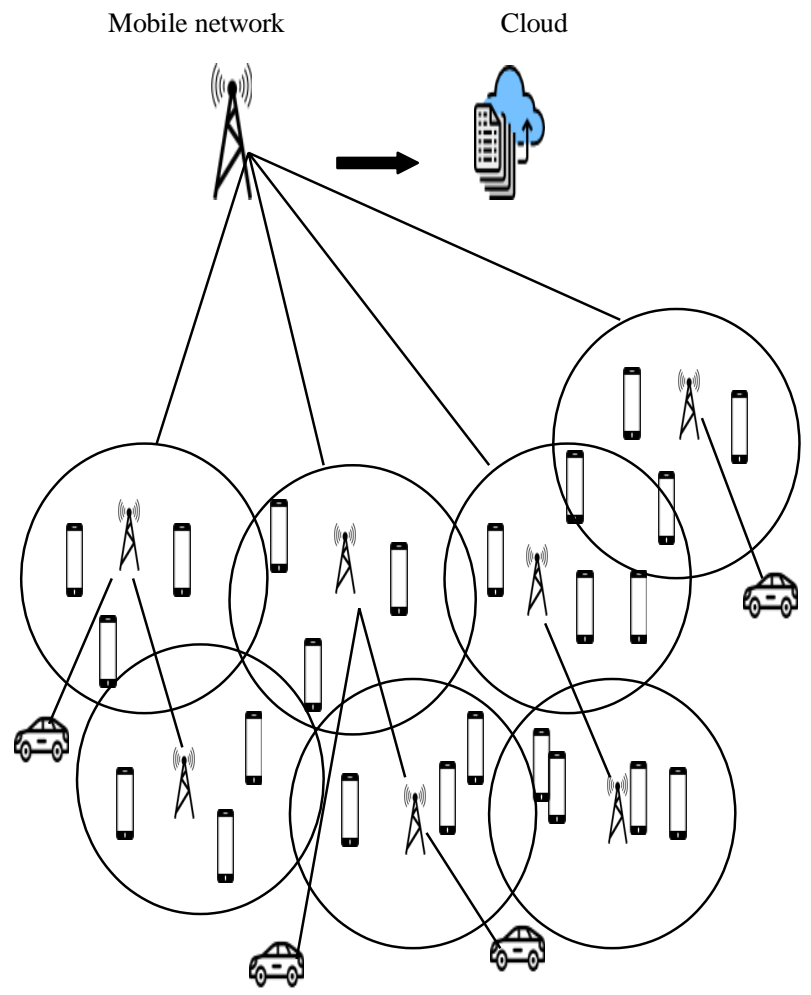

Fig. 2. MCC over Heterogeneous Wireless Data Networks.

This paper essentially spotlights on Mobility Management Challenges and Solutions in Mobile Cloud Computing (MCC) and a wide scope of audits work and endeavors on difficulties and arrangements in MCC are given. Likewise, this work features the principle illuminated research moves identified with cell phones, by taking certain difficulties and parameters like parcel misfortune, delay, correspondence cost, through put and system load. This work intends to be a valuable manual for MCC difficulties and issues and furthermore a point of reference to prepare for additional work and endeavors in MCC space. In second area, a foundation audit and outline is given. In third segment, issue proclamation and proposed philosophy is given. Ultimately, we finish up the paper.

\section{RELATED WORKS}

In this section, we review the year wise related works on mobility management challenges and solutions in MCC.

\section{A. Review between 2000 and 2005}

Corte et al. [26] have concentrated more on the administration of the QoS by utilizing the versatile programming specialists. They have given a reference philosophy which gives the systems administration condition where organize segments and the administrator can act with one another for the better nature of the work. The MAP framework which is pre-accessible in the portable programming stage have two distinct applications, one is to concentrate on asset reservation by utilizing RSVP and next is to give QoS to the pre-accessible traffic which is streaming in a virtual system. In view of this open system, further developed system can be utilized in an entirely adaptable manner. 
However, the hindrance in this is it won't give the security ensure which should be given by the operator execution condition.

Manner et al. [27] have taken diverse procedure and conventions that has given QoS. They have investigated IntServ, DiffServ, blends of the first two things, RTP, INSIGNIA and ITSUMO. Every technique has diverse advantages and downsides. The third-age frameworks plan to give fast versatile access. These models are anyway shut frameworks and very constrained by government specialists and a couple of administrators. The BRAIN and MIND ventures, are likewise contemplating open IP-based portable remote system design. The tasks propose and assess an engineering that offers help for portable QoS, a structure for versatile applications, and a very much characterized interface through which applications can ask for the dimension of administration they require. The design has very much characterized interfaces to permit between operability among systems. Toward the finish of every technique portrayed definitely with the end that none of them truly gives both adaptable and exact QoS.

Hadjadj et al. [28] have grown an enthusiasm for the third era remote IP system and administration advances. This article gives open issues on the smooth and productive help of multicast sight and sound administrations including heterogeneous versatile IPv4 and IPv6 has. In the wake of investigating related takes a shot at this wide territory just as existing yet restricted and halfway arrangements, we have proposed and assessed an incorporated Multicast media passage for IPv4/IPv6 Multimedia Service Transition. The general M3G's design and related useful modules have been depicted and actualized on a Linux-based framework for highlights approval and execution assessment. Progress issues in regards to the client and the flagging control designs have been both tended to. As to the portability part of such administrations, new methodologies and enhancements have been added to the flagging arrangement through a superior coordination of existing sight and sound session the board, versatility and multicast flagging conventions. Thus, straightforward foundation and productive control of half and half interactive media multicast interchanges between portable IPv4-just and IPv6-just mists are conceivable while protecting inheritance IPv4 systems and administrations amid a smooth IPv6transition. With the remote, it required more data transfer capacity which it couldn't ready to give.

Mun et al. [29] have proposed versatile area the executives conspire called NHRP for an IP client on a move over wireless ATM organize. It depends on the NHRP standard, yet improved to help IP portability in wireless ATM systems which have qualities that the purpose of connection to ATM systems changes as often as possible after some time. Rather than the NHRP, where just thinks about settled customers, the recovered location data about the versatile customer from the location goals server in the proposed plan mirrors the present area of the portable customer. Accordingly, the association can be set up straightforwardly in ATM layer. The blame tolerant steering capacity of the proposed plan by joining with either portable PNNI or LRs. Investigative models are determined to affirm the execution of the proposed plan. The execution is estimated as far as the expense. Hunt cost and following expense are gotten. This plan is appeared to be viable than the novel blends. This plan is additionally acquired by the variety of ATM and IPOA scope parameters S and D.

Vincent Lenders et al. [30] have given a novel methodology towards productive and strong administration revelation in portable specially appointed systems. This plan isn't an augmentation to existing impromptu steering conventions or an adaption of leaving administration revelation systems, yet presents and assesses new ideas. All things considered, electric field-based administration revelation utilizes a basic instrument to locate the best course to the nearest administration example: at every hub, the demand is steered towards the steepest angle until it achieves the administration occurrence. The significant favorable position of this methodology be that as it may, is its straightforwardness and lucidity in structure. This technique to perform administration disclosure can without much of a stretch be adjusted to be utilized for extra errands. The main application that rings a bell is parcel directing in MANETs. Rather than sending solicitations to support examples just, a similar component can be utilized to build up correspondence between two gadgets as long as they are exceptionally recognized in the system. Another important property of this methodology is its freedom of the basic system convention. In fact, it isn't just autonomous; it works even without any basic directing convention. Table I shows the summary of reviews between 2000 and 2005 .

TABLE. I. SUMMARY OF REVIEWS BETWEEN 2000-2005

\begin{tabular}{|l|l|l|l|l|}
\hline Ref. No. & Year & Algorithm & Drawback & Performance \\
\hline 26 & 2001 & Mobile agents & $\begin{array}{l}\text { Security } \\
\text { guarantee }\end{array}$ & $\begin{array}{l}\text { Flexible way to } \\
\text { access }\end{array}$ \\
\hline 27 & 2002 & $\begin{array}{l}\text { Access } \\
\text { Networks, MHs, }\end{array}$ & $\begin{array}{l}\text { Didn't } \\
\text { provide QoS }\end{array}$ & $\begin{array}{l}\text { Fast adoption, } \\
\text { fast mobility }\end{array}$ \\
\hline 28 & 2003 & $\begin{array}{l}\text { Multi-media } \\
\text { gateway }\end{array}$ & $\begin{array}{l}\text { lesser } \\
\text { bandwidth }\end{array}$ & $\begin{array}{l}\text { Wireless } \\
\text { network }\end{array}$ \\
\hline 29 & 2004 & $\begin{array}{l}\text { wireless ATM } \\
\text { technology }\end{array}$ & $\begin{array}{l}\text { with higher } \\
\text { data, the } \\
\text { network is not } \\
\text { stable }\end{array}$ & $\begin{array}{l}\text { Fast speed for } \\
\text { wireless }\end{array}$ \\
\hline 30 & 2005 & $\begin{array}{l}\text { Mobile and hoc } \\
\text { networks }\end{array}$ & $\begin{array}{l}\text { low load } \\
\text { balancing }\end{array}$ & $\begin{array}{l}\text { network is } \\
\text { stable, even } \\
\text { when conditions } \\
\text { are dynamic }\end{array}$ \\
\hline
\end{tabular}

\section{B. Review between 2006 and 2008}

The requirement of ubiquitous internet get admission to (e.g., in public transportation systems) is growing. Consequently, mechanisms that permit complete IP networks to be cellular without breaking ongoing connections of the nodes of the internet- work are wanted. The IETF NEMO WG has come up with an IP-level network mobility answer: The Network Mobility (NEMO) [31]. Fundamental Support convention that empowers a network to change its purpose of connection. In this paper we have built up a usage of the NEMO Basic Support convention for Linux, and we have utilized that to tentatively assess the execution of the convention. The NEMO Basic Support convention 
fundamentally comprises in setting a bidirectional passage between the MR and it's HA. This passage adds both starts to finish postponement and bundle overhead. This postponement can be unsatisfactory for some ongoing applications, yet in addition influences the general TCP execution, as it has been for all intents and purposes appeared in this paper. Moreover, the additional parcel overhead expands the data transfer capacity prerequisites for applications. For instance, run of the mill 64 kbps connections would not have the capacity to deal with VoIP Skype calls of a hub having a place with a two-level settled system. Be that as it may, in overlay systems, choice of top notch essential and reinforcement ways is a testing issue because of the sharing of physical connections among overlay ways. Such sharing influences many steering measurements, including joint disappointment likelihood and connection blockage. Henceforth to defeat this issue taken care of by administration Clouds engineering with Planet Lab Internet proving ground alone and a versatile figuring testbed. This paper depicts Service Clouds, a disseminated framework intended to encourage fast prototyping and organization of versatile correspondence administrations. The foundation consolidates versatile middleware usefulness with an overlay organize substrate so as to help dynamic instantiation and reconfiguration of administrations. The Service Clouds design incorporates an accumulation of low-level offices that can be summoned straightforwardly by applications or used to make progressively complex administrations [32].

The architecture of a SDCR system's [33] highlights and CWC were advertised. At that point, as an attainability investigation of SDCR terminal, this paper additionally presented the arrangement and elements of the HWP, SWP, and waveforms and tended to a deliberate information for range detecting period and reconfiguration period by utilizing genuine waveforms. The SDCR terminal executed detecting and reconfiguration of radio correspondence frameworks over $400 \mathrm{MHz}-6 \mathrm{GHz}$. The normal reconfiguration time for every correspondence framework is at most $1650 \mathrm{~ms}$ and real detecting time is inside a few seconds. This improvement is the world's first work. As a further work, field test by utilizing the prototypeon the CWC must be required. These internetworking models might be ordered as tight coupling, free coupling, and distributed systems administration (additionally alluded as no coupling). In any case, these methodologies appear to give constrained internetworking capacity as neither of these structures has effectively tended to the issue of consistent continuation of administrations. So, they presented an [34] internetworking model for WLAN and $3 \mathrm{G}$ cell systems with the 3GPP's IMS structure going about as a referee. It tended to numerous insufficiencies of the current internetworking designs. The most noteworthy advantage is its capacity for arranging and overseeing ongoing sessions with the utilization of the IMS as a brought together session controller. IMS-SIP based terminal and session portability was inspected inside the extent of this system for two situations; that is, while meandering from UMTS to WLAN and from WLAN to UMTS. Results got from the OPNET based recreation stage showed the conduct of handoff for these situations. Reenactment results showed that a make-beforebreak type handoff from UMTS to WLAN is equipped for giving worthy dimensions of consistent congruity of administrations. Results likewise demonstrated a circumstance with information duplication, which must be tended to at a lower layer. Notwithstanding, the break-before-make type handoff situation from WLAN to UMTS demonstrated a short interim of administration intrusion because of its non-covered nature of inclusion.

These days versatile correspondences acquire and more significance. The expanded use requires increasingly complex administrations. In this paper conceivable, future system design is inspected, called BIONETS [35]. For this situation the versatile hubs for the whole system, without devoted spine are available. They seek after the objective of finding an ideal data spread model over some versatility demonstration. The examination covers recently characterized convention called IOBIO, established communicate and a recently created versatile communicate calculation. We run a few recreations with a claim test system made in OMNeT++ so as to choose which one is the ideal data spread strategy for the given versatility condition. The outcomes give us the favorable position to additionally enhance the correspondence in such systems. Notwithstanding, remote handheld gadgets with compelled usefulness, for example, little screen, constrained figuring power, etc. limit the client arranged QoS accommodated remote web surfing. It is troublesome for remote portable clients to peruse vast website page intended for PC clients easily. Consequently by alluding to tremendous processing capacity and capacity asset of distributed computing foundation, another remote web get to mode is proposed [36]. Right off the bat, the framework structure is available. In this manner, the two key segments of framework are portrayed in detail: the one is disseminated website page adjustment motor, which is intended for the reason that the motor can be conveyed by registering cloud dispersed and parallel; the other is circulated site page squares the executives dependent on distributed computing, which is proposed so the site page adjustment motor can be sent sensibly. Besides, a model framework and a lot of assessment tests have been actualized.

Portability has acquainted another measurement with the remote research zones, for example, IP versatility the board conventions and remote specially appointed systems. In this paper they investigate the issues identified with the portability in wireless sensor networks (WSNs). The point of this work is to distinguish upgrades that can be acquired thinking about versatility, perceive its examination challenges. We depict distinctive dimensions of versatility in WSNs and feature the impact of the portability on the execution of WSN conventions [37]. Quality of Service (QoS) provisioning in remote systems rapidly prompts versatility issue because of hard asset portion for every session. Heterogeneous remote condition gives elective assets, however the multifaceted nature of taking care of such framework is high. Henceforth they exhibited a virtual resonance provisioning (VRP) conspire that works together with gathered remote systems in regards to asset accessibility and evaluations asset discharge in not so distant future to keep up prescient asset list for ideal asset usage. Asset usage is additionally upheld by fine-grained QoS administration subclasses, plan to make exact asset allotment. These sub-classes structure subset of QoS classes and expend assets on exact 
requirements of administration and arrangements of physical connections. Results demonstrate that a lot of higher call affirmation rates are accomplished by incorporating virtual asset provisioning and load-adjusting approach [38].

Opportunistic networks, in which hubs shrewdly abuse any pair-wise contact to recognize next bounces towards the goal, are a standout amongst the most intriguing innovations to help the unavoidable systems administration vision. Opportunistic networks permit content sharing between versatile clients without requiring any prior Internet foundation, and endure allotments, long disengagements, and topology unsteadiness as a rule. In this paper they proposed [39] a setting mindful structure for directing and sending in shrewd systems. The structure is general, and ready to have different kinds of setting mindful directing. In this work they additionally present a specific convention, HiBOp, which, by abusing the system, learns and speaks to through setting data, the clients' conduct and their social relations, and utilizations this information to drive the sending procedure. The examination of HiBOp with reference to elective arrangements demonstrates that a setting mindful methodology dependent on clients' social relations ends up being a proficient answer for sending in shrewd systems. We show execution upgrades over the reference arrangements both as far as asset usage and as far as client saw QoS. The methodology appears to be encouraging, in spite of the fact that it is hard to assess its execution with exceedingly portable hubs since it is hard to make sure of $n$ the exactness of the two-bounce neighborhood of a hub. Consequently, to conquer this issue they displayed a far-reaching overview of the best in class for vehicle impromptu systems [40]. They begin by evaluating the conceivable applications that can be utilized in VANETs, to be specific, wellbeing and client applications, and by recognizing their prerequisites. At that point, they characterize the arrangements proposed in the writing as indicated by their area in the open framework interconnection reference show and their relationship to wellbeing or client applications. They break down their focal points and deficiencies and give proposals to a superior methodology. They likewise portray the diverse techniques used to recreate and assess the proposed arrangements. At long last, they finish up with recommendations for a general design that can shape the reason for a commonsense VANET. Table II shows the summary of reviews between 2006 and 2008.

\section{Review between 2008- 2010}

Here searched about notions such as interlocking directorships, communities of practice, learning regions and labor mobility [41]. Here checked on ebb and flow inquire about on information the board and learning move with regards to developments. Explicit consideration is centered around the joining of the board viewpoints into the travel industry look into. They investigated a portion of the key instruments and courses of learning exchange inside the travel industry. There is likewise a developing examination plan on learning the board inside the travel industry however advance is variable with most research being inside the inn segment, where a scope of ongoing investigations have analyzed parts of information exchange. They additionally attract regard for the need to give nearer thoughtfulness regarding the idea of advancements inside the travel industry and to consider these in a learning the executives system. Versatility the board issue happens consequently to beat this issue a practical reenactment of portability for urban remote systems is tended to [42]. As opposed to most other portability displaying endeavors, the majority of the parts of the exhibited versatility model and model parameters are gotten from overviews from urban arranging and traffic designing exploration. The portability demonstrates talked about here is a piece of the UDel Models, a suite of devices for sensible reproduction of urban remote systems. The UDel Models reenactment instruments are accessible on the web.

TABLE. II. SUMMARY OF REVIEWS BETWEEN 2006 AND 2008

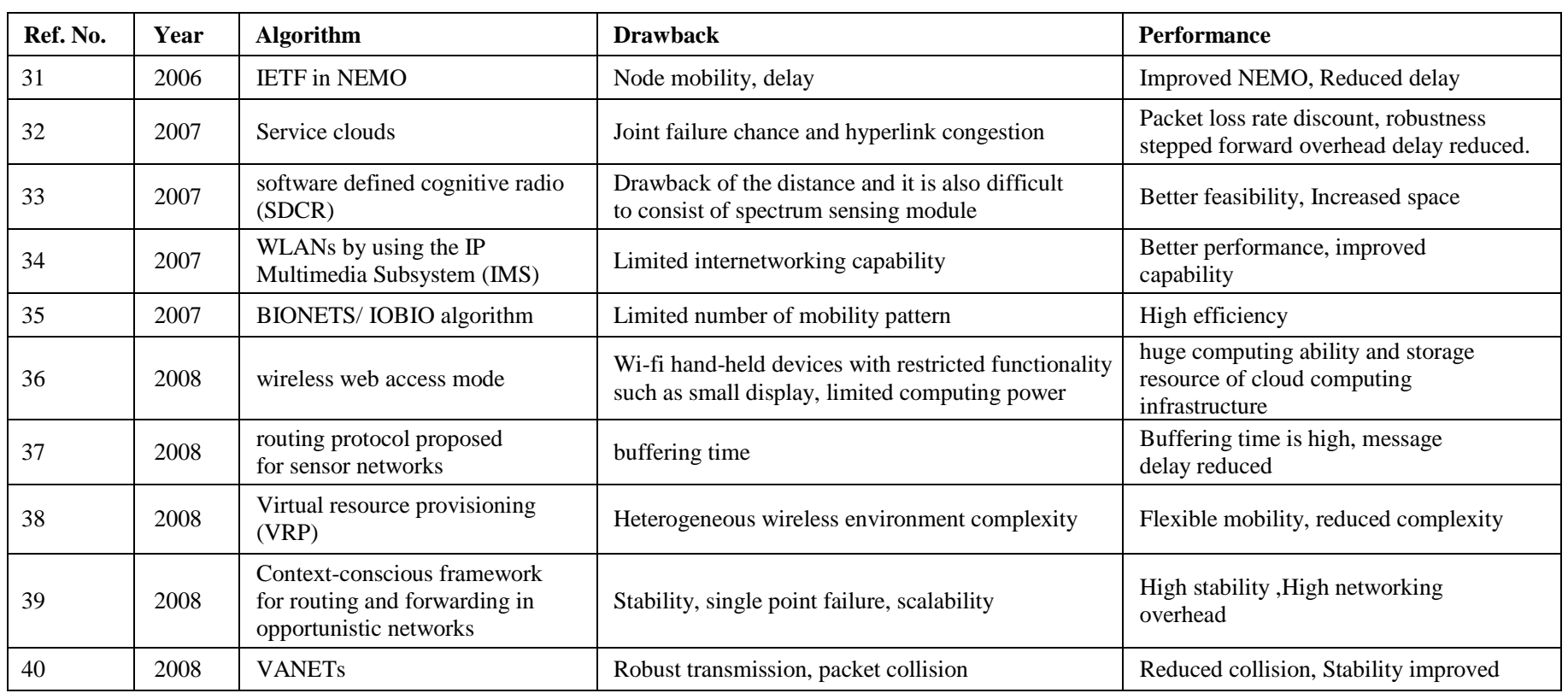


A net-centric announcement, command, and control architecture for a heterogeneous unmanned aircraft system comprised of small and miniature unmanned aircraft are given [43]. An incorporated framework was created utilizing a base up configuration way to deal with reflect and improve the interchange organized correspondence and self-sufficient airplane coordination. The upsides of the methodology are exhibited through a portrayal of the unmanned framework that came about because of utilizing this structure procedure. The equipment framework is portrayed, including both little and smaller than usual unmanned flying machine alongside their particular aeronautics' frameworks. System engineering is depicted that flawlessly consolidates the little airplane's IEEE

802.15.4 components with IEEE 802.11 (WiFi) segments on the little flying machine. Reconciliation of intra vehicle correspondence and administration disclosure is likewise depicted. Various leveled control engineering is exhibited that utilizes the system design to organize the little and smallscale flying machine at a few layers in the control chain of command. Equipment on the up and up shows are performed to approve the abilities of the heterogeneous unmanned airplane framework. They abuse the particular data accessible by the MCC [44] the clients' area, setting, and asked for administrations, and altogether advance the Heterogeneous Access Management plans created for the customary heterogeneous access situations.

They presented design for a portal to provide remote management access to virtualized device management servers hosted in a service cloud [45]. This plan is focused to conceal the subtleties of the gadget the executives behind a standardbased, uniform control interface that can be a cross-stage specialist that can keep running on numerous versatile stages. They will likewise portray quickly the model they are creating as an inner pilot. The Mobile DM programming and the end clients caused a great deal of issues and sobs for critical enhancements. The engineering of SCM [46] a mix of two developing they advances, semantic and distributed computing, for upsetting information access and handling capacities over portable stage. The accentuation lies on decoupling of information preparing and the board from versatile equipment, alongside the way SCM can be utilized to determine issues that have continued over years, and investigating new open doors that SCM may guarantee to offer issues uninformed quality DM programming.

In a Hadoop based system for impromptu versatile distributed computing - they explicitly allude to an exploration paper and the creators' choice to utilize and port Hadoop to construct a virtual distributed computing supplier for cell phones [47]. First and foremost, they are going to layout a short presentation and list the difficulties that they face actualizing a structure for portable distributed computing. They finish up with a short case of other Map-Reduce based MCC system, which accomplished better execution utilizing its very own custom usage. The serious issue is the manner by which to change Hadoop system. To defeat its issue has high data quality. The issue is the extensive scale they present GenLM, a permit the board arrangement reasonable for these situations [48]. It has been worked so as to give a protected and powerful answer for ISVs that need to stretch out their product use to these frameworks. They give ISVs an apparatus chain to actualize self-assertive programming permitting models. In the meantime, they guarantee that licenses are versatile, for example they can be utilized on any asset the client approaches. The issue is the substantial scale.

They overlook the (IMS) as a common coupling mediator for real-time consultation negotiation and management [49]. Queuing idea is based totally on analytical model for assessing the execution of vertical handoff the executives Bett Heyen has interworked 0.33 technology (3G) mobile systems and the Wlans is to be had. The investigation includes vertical handoff execution estimates, as an instance, delay, temporary parcel misfortune, jitter, and flagging overhead/fee. The closing piece of this paper introduces some effects from opnet based recreations to take a look at the logical model and effects. The progressed session control is to propel the making of client subgroups, subsets of a comparable substance collect depending on machine, client and condition putting to the diploma that these are critical for effectiveness [50]. Their traits inside the form of content descriptions are communicated to the media transport to achieve the suitable content material for every session. Table III shows the summary of reviews between 2008 and 2010.

\section{Review between 2011 and 2014}

$\mathrm{Li}$ et al. [51] proposes Urban-traffic the executive's framework utilizing savvy traffic mists to control the traffic in the urban territories. Operator based traffic cloud the board frameworks can utilize the self-rule, portability, and flexibility of versatile specialists to manage dynamic traffic situations. Distributed computing can enable such frameworks to adapt to a lot of capacity and figuring assets required to utilize traffic cloud technique specialists and mass transport information viably. This article audits the historical backdrop of the improvement of traffic cloud control and the board frameworks inside the advancing processing worldview and demonstrates the condition of traffic cloud control and the executive's frameworks dependent on versatile multi-operator innovation. Astute transportation mists could give administrations, for example, choice help, a standard advancement condition for traffic cloud the executives methodologies, etc. With portable operator innovation, an urban-traffic the executives' framework dependent on AgentBased Distributed and Adaptive Platforms for Transportation Systems (Adapts) is both achievable and adequate. Be that the substantial scale utilization of portable operators will prompt the rise of a mind boggling, amazing association layer that requires gigantic registering and power assets. To manage this issue, we propose a model urban-traffic the board framework utilizing savvy traffic cloud mists. 
TABLE. III. SUMMARY OF REVIEWS BETWEEN 2008 AND 2010

\begin{tabular}{|l|l|l|l|l|}
\hline Ref. No. & Year & Algorithm & Drawback & Performance \\
\hline 51 & 2009 & Innovation with tourism & High cost & Knowledge management framework \\
\hline 52 & 2009 & Urban wireless network technique & Slow network & $\begin{array}{l}\text { Network communication and autonomous aircraft } \\
\text { communication }\end{array}$ \\
\hline 53 & 2009 & Heterogeneous aircraft technique & Miniature aircraft is very small & $\begin{array}{l}\text { Capability of heterogeneous unnamed aircraft } \\
\text { system }\end{array}$ \\
\hline 54 & 2010 & Mobile cloudcontroller & It has very low quality & Intelligent radio access management \\
\hline 55 & 2010 & $\begin{array}{l}\text { Virtualized device management } \\
\text { technique }\end{array}$ & It cause the end users & Remote management \\
\hline 56 & 2010 & Theyb technologies & Low information quality & $\begin{array}{l}\text { Data processing and management form } \\
\text { mobile hardware }\end{array}$ \\
\hline 57 & 2010 & Virtual cloud computing technique & $\begin{array}{l}\text { The problem is to how to change the } \\
\text { hadoop framework }\end{array}$ & Custom management \\
\hline 58 & 2010 & Hadoop framework & It has very large-scale & License management \\
\hline 59 & 2010 & $\begin{array}{l}\text { Cellular network and WLAN } \\
\text { Technology }\end{array}$ & It has been delay in information & $\begin{array}{l}\text { Vertical handoff management between interwork } \\
\text { generation }\end{array}$ \\
\hline 60 & 2010 & Context-awaremulticast session & Low efficiency & Session management \\
\hline
\end{tabular}

Sardis et al. [52] have acquainted a novel procedure with enhance the QoS. Ongoing advances in cell phones and system innovations have set new patterns in the manner in which we use PCs and access systems. Cloud computing, where handling and capacity assets are living on the system is one of these patterns. The other is Mobile Computing, where cell phones, for example, advanced mobile phones and tablets are accepted to supplant PCs by joining system availability, versatility, and programming usefulness. Later on, these gadgets are relied upon to flawlessly switch between various system suppliers utilizing vertical handover instruments so as to keep up system availability consistently. This will empower cell phones to get to Cloud Services without interference as clients move around. Utilizing current administration conveyance models, cell phones moving starting with one topographical area then onto the next will continue getting to those administrations from the nearby Cloud of their past system, which may prompt moving a vast volume of information over the Internet spine over long separations. Cloud-Based Mobile Media Service Delivery in which administrations keep running on limited open Clouds and are fit for populating other open Clouds in various topographical areas relying upon administration requests and system status. Utilizing an investigative system, it is contended that as the interest for explicit administrations increments in an area, it may be progressively productive to draw those administrations nearer to that area. This will keep the Internet spine from encountering high traffic stacks because of sight and sound streams and will offer specialist organizations a mechanized asset portion and the executive's system for their administrations.

According to Amoroso et al. [53] in 90's, the endeavor systems were utilized to interface people in general Internet in huge numbers, firewalls shielded confided in substances inside the venture from untrusted access by outside elements. The methodology steadily advanced into the well-known venture security demonstrate, with parts, for example, intrusion detection systems (IDSs)/intrusion prevention systems (IPSs), antivirus (AV) and antispam (AS) channels, risk the board frameworks, and information spillage counteractive action (DLP) devices giving extra help. The subsequent border arranges demonstrate has been a mainstay of insurance structure for security draftsmen for almost three decades. Be that as it may, generally speaking venture trust in this setup has persistently corrupted because of network choices and advancing dangers. Here by analyzing a technique to reestablish this trust utilizing centered insurance methodologies.

Panta et al. [54] propose a framework that makes crafty utilization of portable registering gadgets and specially appointed systems administration to give a transient stockpiling administration to customers in a confined geological area. The primary test is to counterbalance the potential information misfortune brought about by hub versatility with between hub correspondences. The content based on reproduction and hypothesis, such as an administration is possible, is given an adequately high thickness of cell phones. A conveyed correspondence and capacity convention is then utilized for circumstances where every single cell phone are inside correspondence scope of one another, and it is appeared through proving ground investigations and recreation that the convention works accurately and makes effective utilization of storage room and correspondence transfer speed, while expanding the life span of put away information.

Gkatzikis et al. [55] depicted Contemporary cell phones produce substantial heaps of computationally serious undertakings, which can't be executed locally because of the restricted handling and vitality abilities of every gadget. Cloud offices empower cell phones customers to offload their assignments to remote cloud servers, bringing forth MCC. The test for the cloud is to limit the assignment execution and information exchange time to the client, whose area changes because of portability. The nature of administration ensures is 
especially testing in the dynamic MCC condition, because of the time-differing transfer speed of the entrance interfaces, the regularly changing accessible handling limit at every server and the time shifting information volume of each virtual machine. In this article, advocate the requirement for novel cloud models and relocation instruments that viably bring the registering intensity of the cloud nearer to the versatile client. This strategy considers a distributed computing design that comprises of a back-end cloud and a nearby cloud, which is joined to remote access framework (for example LTE base stations). It diagrams distinctive classes of assignment movement arrangements, traversing completely clumsy ones, in which every client or server self-sufficiently settles on its relocation choices, up to the cloud-wide relocation procedure of a cloud supplier. We finish up with a talk of open research issues in the region.

Taleb et al. [56] analyzed that colossal increment in portable information traffic, there is a general pattern toward the decentralization of versatile administrator systems, at any rate partially. This will be additionally encouraged with the virtualization of portable system capacities and the empowering of versatile cloud organizing, whereby versatile systems are made on interest and in an adaptable way. Versatile system decentralization won't be proficient without reconsidering portability the board plans, especially for clients moving for a long separation as well as at a rapid To help such exceedingly portable clients, this paper presents: 1) an information stay entryway $(\mathrm{GW})$ migration strategy dependent on client versatility, history data, and client movement examples, and 2) a handover the executives approach that chooses an objective base station or advanced Node B (eNB) in an approach to limit versatility grapple GW movement. The execution of this plans is assessed by means of Markov show based investigation and through reproductions. Empowering results are gotten, approving the plan targets of the plan.

Zhang et al. [57] depicted telecom cloud give more consideration on area-based applications and administrations. Because of the irregularity and fluffiness of human portability, despite everything it stays open to anticipate client versatility. In this article, it examines the substantial scale client portability follows that are gathered by a telecom administrator. It is discovered that versatile call designs are profoundly associated with the co-area designs at a similar cell tower in the meantime. By extricating such social associations from cell call records put away in the telecom cloud, and further propose a portability expectation framework that can keep running as a foundation level administration in telecom cloud stages. They lead several contextual analyses on portability mindful personalization and prescient asset assignment to expound how this framework drives another method of versatile cloud application.

According to Qi et al. [58] cell phones are turning into the essential stages for some clients who dependably meander around while getting to the distributed computing administrations. From this, the distributed computing is incorporated into the versatile condition by presenting another worldview, portable distributed computing. With regards to portable figuring, the battery life of cell phone is constrained, and it is essential to adjust the portability execution and vitality utilization. Luckily, cloud administrations give the two chances and difficulties to versatility the board. Taking the exercises of cloud administrations getting to into thought, the creators utilized an administration mindful area refresh instrument, which can distinguish the nearness and area of the cell phone without conventional occasional enrollment refresh. Expository model and reproduction are created to examine the new system. The outcomes show that the administration mindful area refresh the board can decrease the area refresh times and handoff flagging, which can effectively spare power utilization for cell phones.

Che et al. [59] looks at that portability is nature on the planet and has advanced into a characteristic element and a key main impetus of things to come system, albeit possibly treated as one viewpoint in a particular system when it started in a cell framework. Going up against developing correspondence ideal models, for example, versatile informal organizations, portable distributed computing, Internet-ofThings, and the desire for universal and consistent network, the current portability the executives advancements face issues, for example, work repetition, framework unpredictability, and wastefulness. The plan reasoning of vertical decoupling the portability substance into administration element and gadget element, and even decoupling the element personality and locator-identifier, are both examined. The plan theory is connected in this capacity reference model and convention reference model of MDN to extract the portability bolster capacities, elements, and standards. At last, the open issues in MDN are talked about.

The Internet of Things (IoT) is rising as one of the real patterns for the following advancement of the Internet, where billions of physical items or things (counting yet not constrained to people) will be associated over the Internet, and a tremendous measure of data information will be shared among them (Yue et al. [60]). Be that as it may, the present Internet was based on a host-driven correspondence show, which was principally intended for fulfilling the need of pairwise distributed interchanges and can't well oblige different propelled information driven administrations supported by the IoT in which clients care about substance and are unmindful of areas where the substance is put away. Web dependent on information-centric networking (ICN) is called DataClouds, to more readily suit information driven administrations. Not the same as existing ICN-based structures, by taking the sharing idea of information driven administrations under the IoT into thought and present consistently and physically framed networks as the fundamental building squares to develop the system with the goal that information could be all the more proficiently shared and spread among intrigued clients. It is additionally expand on a few basic structure difficulties for the Internet under this new design and demonstrate that DataClouds could offer more productive and adaptable arrangements than conventional ICN-based models. Table IV shows the summary of reviews between 2011 and 2014. 
TABLE. IV. SUMMARY OF REVIEWS BETWEEN 2011 AND 2014

\begin{tabular}{|c|c|c|c|c|}
\hline Ref. No. & Year & Algorithm & Drawback & Performance \\
\hline 51 & 2011 & $\begin{array}{l}\text { City-site visitors c control system } \\
\text { using clever visitors clouds }\end{array}$ & $\begin{array}{l}\text { Cost is high, operating frequency is up to } 2.66-\mathrm{ghz} \text {, } \\
\text { several pcs or a high performance server are needed } \\
\text { to deal with the experimental scale of several } \\
\text { hundreds of intersections }\end{array}$ & $\begin{array}{l}\text { High performances between the } \\
\text { number of intersections and evolution } \\
\text { time }\end{array}$ \\
\hline 52 & 2013 & $\begin{array}{l}\text { Cloud-based cell media provider } \\
\text { shipping }\end{array}$ & $\begin{array}{l}\text { now not scale to cowl the future desires of cell } \\
\text { customers, lack of latency as a user movements } \\
\text { while streaming a video }\end{array}$ & $\begin{array}{l}\text { efficient management of community } \\
\text { resources while offering a excessive } \\
\text { QoS for the clients }\end{array}$ \\
\hline 53 & 2013 & Focused protection strategies & $\begin{array}{l}\text { Cost implications of this technique is high, } \\
\text { complexity will at once relate to the diploma of use. }\end{array}$ & $\begin{array}{l}\text { The trust degree is high as compared to } \\
\text { the other technique. }\end{array}$ \\
\hline 54 & 2013 & $\begin{array}{l}\text { Distributed communication and } \\
\text { storage protocol }\end{array}$ & $\begin{array}{l}\text { Offset the ability information loss resulting from } \\
\text { node mobility }\end{array}$ & $\begin{array}{l}\text { Analyzed the parameters like effect of } \\
\text { node mobility and failures, } \\
\text { convergence time, effect } \\
\text { of limited node capacity, }\end{array}$ \\
\hline 55 & 2013 & $\begin{array}{l}\text { Cloud computing structure that } \\
\text { includes a returned-stop cloud and a } \\
\text { nearby cloud }\end{array}$ & $\begin{array}{l}\text { Decrease the undertaking execution and records } \\
\text { switch time to the consumer, large-scale datacenter } \\
\text { networks which include multiple dispersed server } \\
\text { centers. }\end{array}$ & Efficient task scheduling \\
\hline 56 & 2014 & $\begin{array}{l}\text { Data anchor gateway }(\mathrm{GW}) \\
\text { relocation method, a handover } \\
\text { management policy }\end{array}$ & Data traffic and the interference & $\begin{array}{l}\text { Mobility, selection of target base } \\
\text { station }\end{array}$ \\
\hline 57 & 2014 & $\begin{array}{l}\text { Mobility prediction machine that } \\
\text { may run as an infrastructure-degree } \\
\text { carrier }\end{array}$ & $\begin{array}{l}\text { Difficult to identify the similar patterns when they } \\
\text { are too congested. }\end{array}$ & $\begin{array}{l}\text { The massive-scale user mobility lines } \\
\text { which can be amassed by using a } \\
\text { telecom operator, cellular call styles. }\end{array}$ \\
\hline 58 & 2014 & $\begin{array}{l}\text { Service-aware location update } \\
\text { mechanism }\end{array}$ & $\begin{array}{l}\text { Battery life of mobile device is restricted, mobility } \\
\text { performance is also } \\
\text { limited }\end{array}$ & $\begin{array}{l}\text { Service-aware location update } \\
\text { management is performed. }\end{array}$ \\
\hline 59 & 2014 & Mobility-driven network (MDN) & $\begin{array}{l}\text { Function redundancy, system complexity, and } \\
\text { inefficiency }\end{array}$ & $\begin{array}{l}\text { Analysis of the mobility support } \\
\text { functions }\end{array}$ \\
\hline 60 & 2014 & $\begin{array}{l}\text { Architecture based on information- } \\
\text { centric networking (ICN }\end{array}$ & $\begin{array}{l}\text { Pair-wise peer-to- peer communications are } \\
\text { implemented in advance }\end{array}$ & $\begin{array}{l}\text { For the better performances of data- } \\
\text { centric services. }\end{array}$ \\
\hline
\end{tabular}

\section{E. Review between 2015 and 2018}

$\mathrm{Li}$ et al. [61] to more readily suit information driven administrations. Not the same as existing ICN-based structures, by taking the sharing idea of information driven administrations under the IoT into thought and present consistently and physically framed networks as the fundamental building squares to develop the system with the goal that information could be all the more proficiently shared and spread among intrigued clients. It is additionally expand on a few basic structure difficulties for the Internet under this new design and demonstrate that DataClouds could offer more productive and adaptable arrangements than conventional ICN-based models.

Aissioui et al. [62] have taken a shot at 5G versatile system design is required to offer abilities to oblige the relentless ascent in portable information traffic and to meet further stringent inactivity and dependability necessities to help assorted high information rate applications and administrations. MCC in 5G has risen as a key worldview, promising to increase the capacity of cell phones through provisioning of computational assets on interest, and empowering asset compelled cell phones to offload their preparing and capacity prerequisites to the cloud framework. Follow Me Cloud (FMC), thusly, has risen as an idea that enables consistent relocation of administrations as per the comparing clients' versatility. In the interim, Software Defined Networking ( $\mathrm{SDN}$ ) is a new worldview that allows the decoupling of the control and information planes of customary systems and gives programmability and adaptability, enabling the system to progressively adjust to changing traffic examples and client requests. While the SDN usage is picking up force, the control plane is as yet experiencing adaptability and execution worries for an extremely expansive system. These adaptability and execution issues with regards to $5 \mathrm{G}$ versatile systems by presenting a novel SDN/OpenFlow-based design and control plane structure custom fitted for MCC-based frameworks and all the more explicitly for FMC-based frameworks where portable hubs and system administrations are liable to imperatives of developments and relocations. In spite of an incorporated methodology with a solitary SDN controller, this methodology allows the circulation of SDN/OpenFlow control plane on a two-level progressive engineering: a first level with a global controller G-FMCC, and second level with several local controllers LFMCC(s).

Rahimi et al. [63] have taken a shot at the ideal and reasonable administration distribution for an assortment of portable applications (single or gathering and communitarian versatile applications) in portable distributed computing. The structure to show portable applications as an area location- 
time workflows (LTW) of errands; here clients versatility designs are meant portable administration use designs. An ideal mapping of LTWs to layered cloud assets considering different QoS objectives such application delay, gadget control utilization and client cost/cost is a NP-difficult issue for both single and gathering based applications. A proficient heuristic calculation considered MuSIC that can perform well $(73 \%$ of ideal, $30 \%$ superior to straightforward techniques), and scale well to a substantial number of clients while guaranteeing high versatile application QoS. At that point assess MuSIC and the 2-level versatile cloud approach by means of usage (on certifiable mists) and broad reenactments utilizing rich portable applications like serious flag preparing, video gushing and mixed media record sharing applications.

Kumar et al. [64] have worked with the across the board ubiquity and utilization of ICT around the globe, there is expanding enthusiasm for supplanting the conventional electric lattice by the brilliant network sooner rather than later. Many savvy gadgets exist in the shrewd matrix condition. These gadgets may impart their information to each other utilizing the ICT-based foundation. The examination of the information produced from different keen gadgets in the savvy lattice condition is a standout amongst the most difficult assignments to be executed as it changes as for parameters, for example, measure, volume, speed, and assortment. The yield of the information examination should be exchanged to the end clients utilizing different systems and keen machines. Be that as it may, at times systems may wind up over-burden amid such information transmissions to different savvy gadgets. Thus, huge deferrals might be caused, which influence the general execution of any actualized arrangement in this condition. We explore the utilization of VDTNs as one of the answers for information dispersal to different gadgets in the shrewd network condition utilizing portable edge registering. VDTNs utilize the store-and-convey forward component for message scattering to different keen gadgets so that postponements can be diminished amid over-burdening and clog circumstances in the center systems.

Ha et al. [65] have taken a shot at one of the significant difficulties in 6LoWPAN is to give nonstop administrations while versatile hubs' developments with limiting system blocked off time caused because of handoffs. Despite the fact that MIPv6, HMIPv6, and PMIPv6 are regularly acknowledged principles to address this in IP systems, they can't characteristically evade the corruption in correspondence quality amid handoff, since they are not planned with thought of compelled hub systems like 6LoWPAN. A quick versatility, the executives' convention for 6LoWPAN, named intraMARIO is proposed. To limit handoff deferral and improve administration accessibility, intra-MARIO presents three critical parts, which are a quick rejoin plot for handoff the board with a versatile surveying-based development discovery and multi-bounce pointer sending plans for area the executives. To legitimize the adequacy, they have led the broad recreations by contrasting intra-MARIO and earlier plans like an essential versatility the executives plot and a PMIPv6-based convention.

Mazza et al. [66] have dealt with expanding urbanization dimension of the total populace has driven the advancement of a brilliant city geographic framework, imagined as a completely associated wide region portrayed by the nearness of a large number of shrewd gadgets, sensors, and handling hubs went for circulating knowledge into the city. In the meantime, the inescapability of remote advances has prompted the nearness of heterogeneous systems, working at the same time in a similar city region. The UMCC system is produced, presenting a portable distributed computing model portraying the flows of information and tasks occurring in the savvy city. A unified offloading component is utilized where correspondence and figuring assets are mutually overseen, permitting load adjusting among the different substances in the earth, appointing both correspondence and calculation undertakings so as to fulfill the savvy city application prerequisites.

Jeon et al. [67] have taken a shot at plan and sending of novel portable system engineering, inspired by the difficulties getting from the unstable increment in information traffic on administrator systems, is a squeezing issue in the present media communications. Distributed mobility management (DMM) acquaints a key thought with handle the traffic bottlenecks that sway current portable systems, by proposing the arrangement of circulated portability stay directs close toward terminal areas. A far-reaching examination and correlation consider methodically breaking down accessible plan alternatives have not yet been given. At that point distinguish fundamental structure contemplations and their hidden alternatives, contrasting their effect on client and system execution.

Ahmad et al. [68] have dealt with MCC is a creating innovation that helps with enhancing the nature of the versatile administrations. Since the expansion in portable assets, the specialists have stepped up with regards to take into consideration asset sharing among heterogeneous cell phones. Subsequently, to structure framework design for versatility models and asset sharing are key issues that require most extreme endeavors to be settled to accomplish foreseen destinations. Framework engineering dependent on the various leveled asset sharing component for MCC and the framework design is isolated into three spaces, for example, Global Cloud Server (GCS), Local ISP Server (LIS), and Gateway Server (GWS). A foglet selection scheme is evolved based totally on the Technique for Order of Preference by Similarity to Ideal Solution (TOPSIS) decision mechanism. Diverse parameters consisting of delay, jitter, bit error rate, packet loss, communication cost, response time, and network load are considered for choosing the most appropriate network.

Chaudhary et al. [69] have taken a shot at, exponential increment in the quantity of Internet-empowered gadgets, which has brought about prominence of haze and distributed computing among end clients. End clients expect high information rates combined with secure information access for different applications executed either at the edge (haze processing) or in the center system (distributed computing). Be that as it may, the bidirectional information stream between the end clients and the gadgets situated at either the edge or center may cause blockage at the cloud server farms, which are utilized mostly for information stockpiling and information investigation. The high portability of gadgets (e.g., vehicles) 
may likewise represent extra difficulties as for information accessibility and handling at the center server farms. Henceforth, there is a need the majority of the assets accessible at the edge of the system to guarantee the smooth execution of end-client applications. The NSC administration demonstrate mechanizes the virtual assets by affixing in an arrangement for quick processing in both registering advances. This engineering additionally bolsters information investigation and the executives concerning gadget versatility. Besides, we additionally contrast the center and edge registering and admiration to the kind of hypervisors, virtualization, security, and hub heterogeneity. By concentrating on hubs' heterogeneity at the edge or center in the $5 \mathrm{G}$ condition, we additionally present security difficulties and conceivable kinds of assaults on the information shared between different gadgets in the $5 \mathrm{G}$ condition.

Enayet et al. [70] have chipped away at, the shrewd city idea, which includes numerous controls, for instance, brilliant human services, keen transportation, and savvy network, has turned out to be famous on account of its capacity to enhance urban residents' personal satisfaction. In any case, most administrations in these regions of shrewd urban areas have progressed toward becoming information driven, in this way producing huge information that require consistent ongoing access, sharing, putting away, preparing, and examination anyplace whenever for clever basic leadership to enhance expectations for everyday comforts. MCC can assume an imperative job by enabling a cell phone to get to and on-load huge information related errands to incredible cloudlet servers joined to numerous remote APs, along these lines guaranteeing that the QoS requests of end clients are met. The availability of cell phones with a given AP isn't consistent, yet rather sporadic with shifting sign qualities. Besides, the heterogeneity of the cloudlet assets and the enormous information application demands place extra difficulties in settling on ideal code execution choice. Table $\mathrm{V}$ shows the summary of reviews between 2015 and 2018.

TABLE. V. SUMMARY OF REVIEWS BETWEEN 2015 AND 2018

\begin{tabular}{|c|c|c|c|c|}
\hline Ref. No. & Year & Algorithm & Drawback & Performance \\
\hline 61 & 2015 & $\begin{array}{l}\text { Mechanisms and demanding situations } \\
\text { on Mobility-Augmented Service } \\
\text { Provisioning for Mobile Cloud } \\
\text { Computing }\end{array}$ & $\begin{array}{l}\text { Pair-wise peer-to-peer communications } \\
\text { are not implemented in advance. }\end{array}$ & $\begin{array}{l}\text { Enhanced capacity of poor - } \\
\text { resource mobile devices by using service } \\
\text { provided in remote cloud }\end{array}$ \\
\hline 62 & 2015 & $\begin{array}{l}\text { FMC based on LISP (Local/Identifier } \\
\text { Separation Protocol). }\end{array}$ & $\begin{array}{l}\text { Difficult to identify the similar } \\
\text { patterns when they are too congested. }\end{array}$ & $\begin{array}{l}\text { Plays higher postpone performance, and } \\
\text { therefore, a quicker dealing with of } \\
\text { regulations installation in contrast with } \\
\text { centralized FMCC architecture }\end{array}$ \\
\hline 64 & 2016 & Virtual machine migration approach. & Data traffic and the interference. & $\begin{array}{l}\text { Limit the energy consumption at the facts } \\
\text { center. }\end{array}$ \\
\hline 65 & 2016 & $\begin{array}{l}\text { Intra-PAN mobility } \\
\text { management scheme. }\end{array}$ & $\begin{array}{l}\text { No longer scale to cowl the destiny } \\
\text { wishes of cell customers, lack of } \\
\text { latency. }\end{array}$ & $\begin{array}{l}\text { Reduces handoff delay, it minimizes the } \\
\text { hyperlink disconnection time of MNS and } \\
\text { packets loss during their handoffs. }\end{array}$ \\
\hline 67 & 2017 & $\begin{array}{l}\text { Distributed mobility } \\
\text { management. }\end{array}$ & $\begin{array}{l}\text { Cost is high, operating frequency is } \\
\text { up to } 2.66 \text {-ghz, several pcs or a high } \\
\text { performance }\end{array}$ & $\begin{array}{l}\text { Lessen the revenue- outstripping fees } \\
\text { whilst stretching their community } \\
\text { capacities with information offloading } \\
\text { technology. }\end{array}$ \\
\hline 68 & 2017 & $\begin{array}{l}\text { Hierarchical resource management } \\
\text { scheme for MCC. }\end{array}$ & $\begin{array}{l}\text { Cost implications of this technique is } \\
\text { high. }\end{array}$ & Energy can be drastically reduced. \\
\hline 69 & 2017 & $\begin{array}{l}\text { They proposed architecture to defend } \\
\text { the cloudlet servers from viable DDOS } \\
\text { attacks. }\end{array}$ & $\begin{array}{l}\text { Limit the mission execution and records } \\
\text { switch time to the consumer, large- } \\
\text { scale datacenter networks which consist } \\
\text { of more than one dispersed server } \\
\text { centers. }\end{array}$ & $\begin{array}{l}\text { Lessen the capital expenditure (CAPEX) } \\
\text { and operational expenditure (OPEX), permit } \\
\text { short failure recovery, and simplify the } \\
\text { installation/modification of latest offerings } \\
\text { on the SDN controller. }\end{array}$ \\
\hline 70 & 2018 & $\begin{array}{l}\text { Mobility-conscious best aid allocation } \\
\text { architecture, specifically mobi-het. }\end{array}$ & $\begin{array}{l}\text { Offset the potential data loss caused } \\
\text { by node mobility. }\end{array}$ & $\begin{array}{l}\text { Better performance in timeliness and } \\
\text { reliability. }\end{array}$ \\
\hline
\end{tabular}




\section{Problem Methodology AND Proposed System MODEL}

\section{A. Problem Methodology}

Aissioui et al. [71] have foreseen a versatile technique which is gotten from SDN/Open-Flow auxiliary plan and a control plane structure. They are commonly adjusted for versatile distributed computing frameworks and Follow Me Cloud (FMC)- related frameworks. The condition of $5 \mathrm{G}$ portable systems are predominantly utilizes to deal with the plane structure for MCC-related frameworks where versatile hubs and system administrations are demonstrating restriction of exercises and movements. Also, the disparity of unified strategy through lone SDN controller is encouraging to dispense the SDN/Open-Flow control plane on a two-level various leveled auxiliary structure which are containing first stage among a worldwide controller of G-FMCC and second stage among various neighborhood controller. The appraisal outcomes are gained by methods for examination. Also, this clarification is ensuring the upgraded control plane association, introduction support, and system asset protection. MCC is a focalized innovation included three foundation heterogeneous advancements, to be specific portable processing, distributed computing, and systems administration. The forthcoming heterogeneous $5 \mathrm{G}$ arrange underscores on an emotional increment in the transmission pace of MCC traffic. With more clients working at high rates, the sort of information shared over the system will be intricate and a dominant part of it will incorporate video traffic. Such mind boggling structure of traffic and substantial burden over the parts of the system are hard to control. Further, the portability of clients indicates this issue and makes it hard to oversee and work the system with no breakdown. In this manner, it is essential to control traffic just as deal with the versatility of clients to give effective correspondence, which can bolster video traffic at high conveyance rates. Also, the essential parameters influence the presentation of system as the tremendous assortment of cell phones with various Operating Systems (OSs), stages, and remote system measures. The up and coming $5 \mathrm{G}$ systems target giving rapid correspondences to clients independent of their development. With an expansion in the quantity of gadgets and the system achieving its pinnacle size, because of thick sending, it gets essential to oversee and control versatility for effective correspondence. Portability the executives requires various activities at a similar example, which incorporate ideal course choice, versatile stay support, client design distinguishing proof, and administration handoffs [72].

An energy efficient mobility management in mobile cloud computing (E2M2C2) system utilizes the optimal cluster selection, cloud selection and route selection to obtain energy efficient mobility management. The main involvement of proposed E2M2C2 system is summarized as follows:

- In E2M2C2 system, the Cluster Head Selection (CHS) Algorithm is used for reducing energy consumption in networking and data transmission phase.

- Various parameters used for cluster head selection process are: energy consumption, delay, handoff, overhead, delivery ratio.

- An Elective Repeat Multi-objective Optimization $\left(\mathrm{ERMO}^{2}\right)$ Algorithm is used to compute the best cloud among various in the network.

- Various parameters used for best cloud election process are: delay, packet loss rate, energy consumption, through put and fairness index.

- The Back Track Searching (BTS) Algorithm used to compute the congestion and select optimal routes between the serving terminals.

- Various parameters used for best cloud election process are: delay, packet loss rate, energy consumption, through put and fairness index.

\section{B. System Model of Proposed E2M2MC2 System}

The system model of proposed E2M2C2 framework is appears in Fig. 3, which utilizes the follow me cloud (FMC) idea, which permits the migration of administrations gave to clients contingent upon their developments. Administrations are along these lines consistently gave from server farm areas that are ideal for the present areas of the clients. This furnishes clients with improved QoS/QoE, simultaneously and it permits saving administrators' system assets by getting away system traffic to server farms through the closest focuses contrasted and clients' areas. Another bit of leeway of FMC innovation is that movement of administrations is consistent and straightforward to clients. MCC system utilize both the data storing and the data dealing with occur outside of the mobile phone. Concerning definition, portable applications move the preparing power and limit from the phone phones to the Cloud. It may be thought the union of the distributed computing and versatile condition [72].

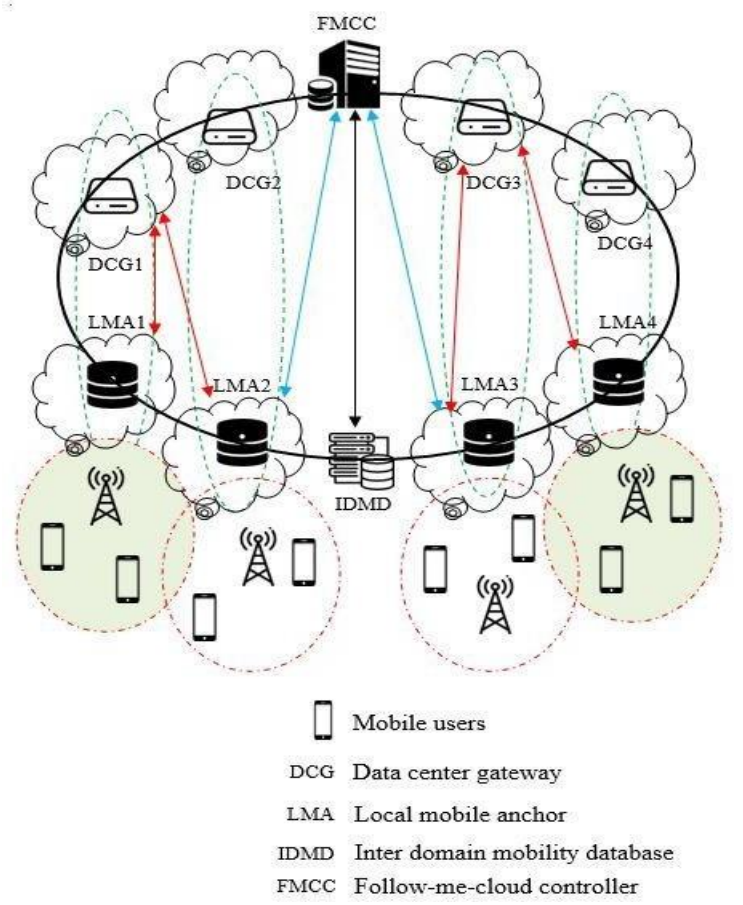

Fig. 3. System Model of Proposed E2M2MC2 System Block Diagram. 
1) Cloud clusters group optimal algorithm: Clustering is a scarce and non-renewable is energy efficient design and the performance analysis requires proper model for measure proper energy consumption of network interfaces. The possible states of energy consumption in mobile nodes are transmit, receive, idle and sleep. The first two sate are when the mobile nodes is transmitting/receiving packets respectively, the idle state is when the mobile node is waiting for transmitting packets and the sleep state can neither transmit/receive packets. The link-metric cost $\left(\mathrm{L}_{\mathrm{c}}\right)$ associated with the each packet at each mobile node is defined as the total incremental cost $\left(\mathrm{C}_{\mathrm{t}}\right)$ proportional to the packet size $\left(\mathrm{P}_{\mathrm{s}}\right)$ and a fixed $\operatorname{cost}\left(\mathrm{C}_{\mathrm{f}}\right)$ associated with the routing.

$L_{c}=C_{t} \times P_{s} \times C_{f}$

The average energy consumption $\left(E_{a}\right)$ is written as follows:

$E_{a}=a L_{c} P_{a}+b L_{c} P_{s}$

where $P_{a}$ is the power consumed by the mobile node with the cost of $\mathrm{L}_{\mathrm{c}}$ and ' $\mathrm{a}$ ' is the rate of occurrence, and $P_{s}$ that is the power consumed by the mobile node with $\operatorname{cost} \mathrm{L}_{\mathrm{c}}$ and has the occurrence rate ' $b$ '. Given the diversity of energy collection methods, and the wide range of application profiles it is not possible to create a generic model, however, the essential criterion is that the energy stored $\left(E_{s t}\right)$ in the node must be at least equal with the energy used for its operation in the time interval $T_{2}-T_{1}$.

$$
E_{s t}=\int_{T_{1}}^{T_{2}}\left(P_{c}-P_{c s}\right) d t
$$

where $P_{c}$ is the power consumed by the mobile node in the time interval $T_{2}-T$ and $P_{c s}$ is the power collected and stored power in the same timeline.

General building of mobile nodes arranged around a single power supply, which for the periods in which handset, when they are either ended by electronic switches, or set into rest state, it is ideally to be set to make a lower yield voltage through component vapor sorption strategy in light of the fact that the imperativeness viability of the microcontroller will increase in the midst of these seasons of rest states. The total energy consumed (Total EC) by mobile node will be represented as follows:

$\operatorname{Total}_{E C}=\sum_{k=0}^{T} \frac{\left(E_{a}(t)+E_{s t}(t)\right) L_{c}}{E_{\eta_{D C-D C}}}$

where $E_{\eta_{D C-D C}}$ is the energy consumption of DC-DC converter.
Once the distance between two neighborhoods exceed a certain extent, the transmission signal will not be received correctly by receiver i.e. link failure. The received signal strength at any node from its neighbor node affects. If a node receives a strong signal from a neighbor then the link between them is considered as stable, otherwise the link is considered as unstable. The difference of two signal strengths received at a node at two different times. The signal strength is stronger, it means that two nodes would be closer and the link between them would have longer lifetime. It is calculated in order to determine whether the node is within the transmission range or not. There are three main radio propagation models are free space, two-ray ground reflection and shadowing model. Simply, the received signal strength is defined as a ratio of the received power $\left(\mathrm{P}_{\mathrm{r}}\right)$ to the reference power $\left(\mathrm{P}_{\mathrm{ref}}\right)$.

$$
R=10 \log \frac{P_{r}(x)}{P_{r e f}}
$$

The configured transmission power at the transmitting device $\left(P_{t}\right)$ in total energy consumption is directly affects the receiving power at the receiving device $\left(\mathrm{P}_{\mathrm{r}}\right)$.

$P_{r}=P_{t} L_{c} \frac{\lambda^{2}}{4 \pi d^{2}}$

where, $\mathrm{d}$ is the distance between transmitter and receiver mobile node; $\lambda$ is the control parameter taken from the mobility of mobile nodes.

2) Cloud selection using elective repeat multi-objective optimization $\left(E R M O^{2}\right)$ algorithm: The below Fig. 4 flowchart describes the flow of $\mathrm{ERMO}^{2}$ algorithm.

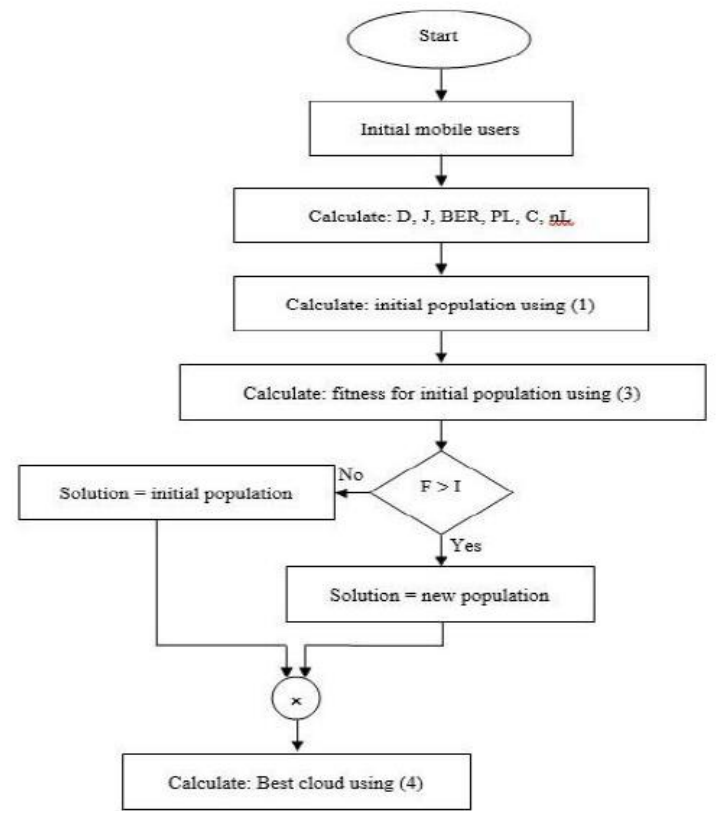

Fig. 4. Working Flow of Proposed E2M2C2 System-Cloud Selection using ERMO $^{2}$ Algorithm. 


\section{RESUlt ANALYSIS}

The mobile cloud computing structures is dissected for the presentation perspective. Versatile cloud design builds asset accessibility by utilizing enormous number of close by cell phones in broad daylight places like shopping center, film, and air terminal assistance accessibility is expanding recognizably. It additionally upgrades security as a result of the dynamic parceling of the correspondence divert in the between cell phone and cloud server. In this segment, we present the assessment of our energy efficient mobility management in mobile cloud computing (E2M2C2) system and it compared with the existing distributed follow me cloud controller (DFMCC). The presentation of proposed E2M2C2 framework is investigated by the diverse testing situations: effect of versatile client thickness and their speed. The quantity of versatile clients is fluctuated from 30 to 110 in first test and the portable client speed is changed from 20 to $100 \mathrm{~ms}$ in the subsequent situation. For this testing, we utilize four DCG and LMA, one IDMD and one FMCC with high thickness portable clients. The two tests are actualized in Network Simulator (NS2) device with $1000 \times 1000 \mathrm{~m} 2$ arrange size. The recreation parameters are condensed in Table VI.

TABLE. VI. SimULATION PARAMETERS

\begin{tabular}{|l|l|}
\hline Parameters & Values \\
\hline Number of Mobile nodes & $30,50,70,90,110$ \\
\hline Mobile user speed (ms) & $20,40,60,80,100$ \\
\hline Number of DCG & 4 \\
\hline Number of IMA & 4 \\
\hline Number of IDMD & 1 \\
\hline Number of FMCC & 1 \\
\hline Network size & $1000 \times 1000 \mathrm{~m} 2$ \\
\hline Traffic model & Constant bit rate \\
\hline Simulation time (s) & 100 \\
\hline
\end{tabular}

1) Effect of mobile nodes: In this situation, we fluctuating the quantity of hub from 30 to 110 with the fixed speed as 60 $\mathrm{ms}$ and the presentation of proposed E2M2C2 is contrasted and the current DFMCC framework. Fig. 5 shows the bundle misfortune pace of proposed E2M2C2 and existing DFMCC framework. The plot obviously delineates the parcel misfortune pace of proposed E2M2C2 framework is exceptionally low regarding $41 \%$ less contrasted with existing DFMCC framework. Fig. 6 shows the vitality utilization of proposed E2M2C2 and existing DFMCC framework. The plot obviously delineates the vitality utilization of proposed E2M2C2 framework is low as far as $39 \%$ less contrasted with existing DFMCC framework. Fig. 7 shows the throughput of proposed E2M2C2 and existing DFMCC framework. The plot obviously delineates the throughput of proposed E2M2C2 framework is extremely high as far as $24 \%$ high contrasted with existing DFMCC framework. Fig. 8 shows the reasonableness list of proposed E2M2C2 and existing DFMCC framework. The plot obviously delineates the decency record of proposed E2M2C2 framework is high regarding $44 \%$ high contrasted with existing DFMCC framework. Fig. 9 shows the deferral of proposed E2M2C2 and existing DFMCC framework. The plot unmistakably portrays the deferral of proposed E2M2C2 framework is low as far as $20 \%$ high contrasted with existing DFMCC framework.

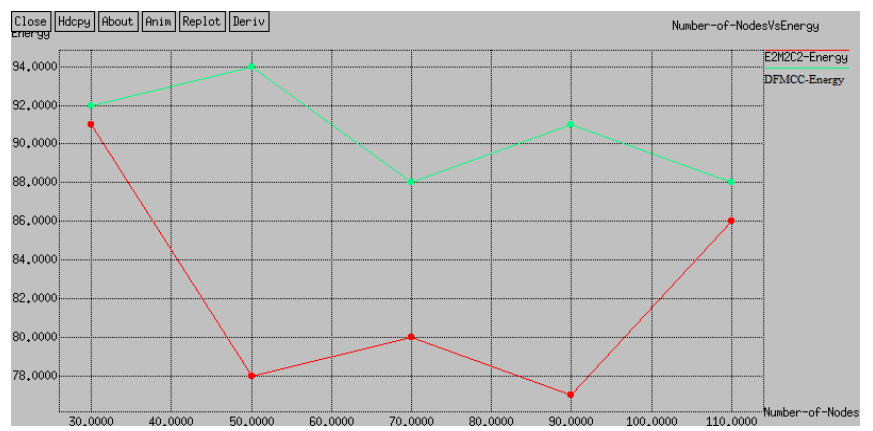

Fig. 5. Energy Consumption Comparison with Effect of Mobile Nodes.

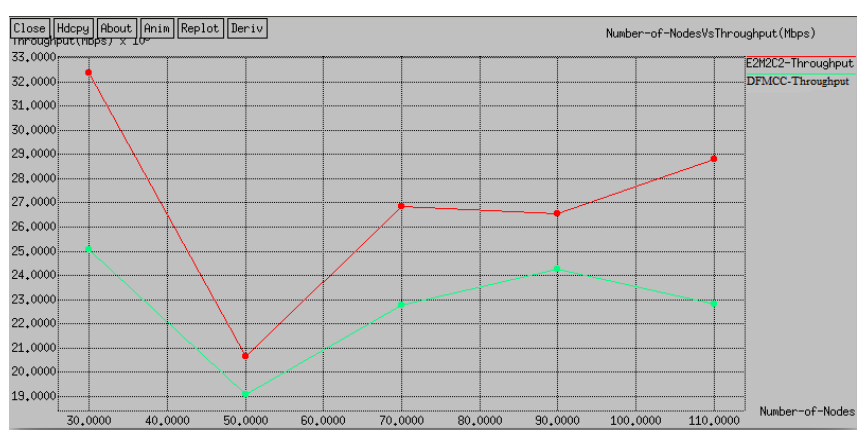

Fig. 6. Throughput Comparison with Effect of Mobile Nodes.

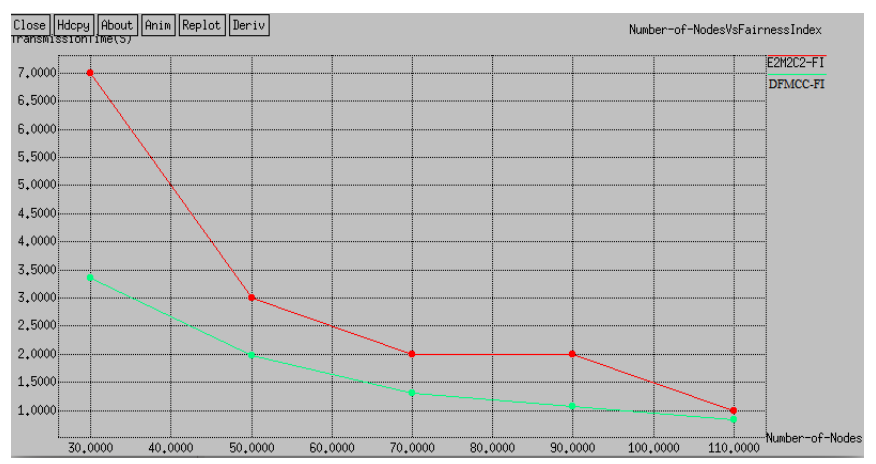

Fig. 7. Fairness Index Comparison with Effect of Mobile Nodes.

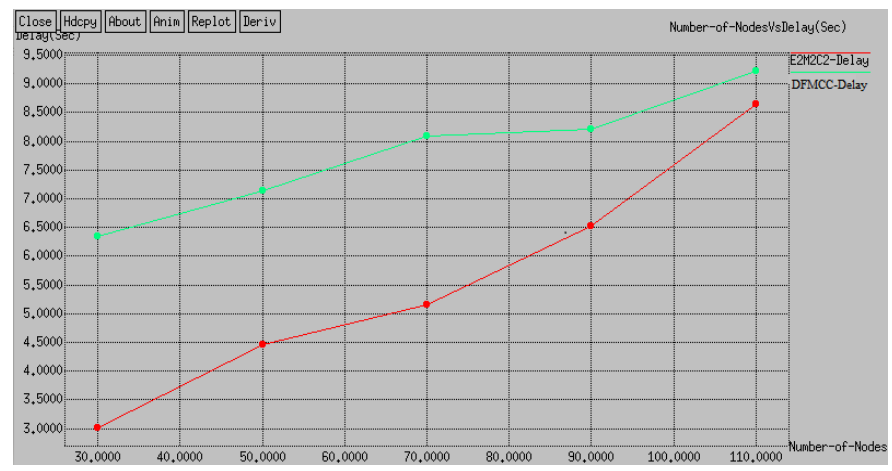

Fig. 8. Delay Comparison with Effect of Mobile Nodes. 


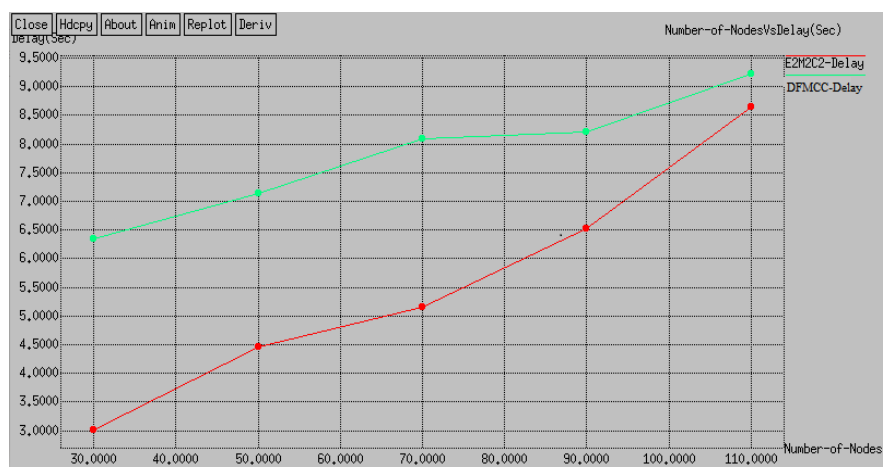

Fig. 9. Delay Comparison with effect of Mobile Nodes.

\section{CONCLUSION}

In this paper, we have embraced an efficient writing survey of versatility the executives in MCC, so as to comprehend the pattern of research interests so far in MCC, regarding the least and most inquired about issues. We had the option to feature a portion of the difficulties in MCC, for example, protection, security and trust, adaptation to non-critical failure, portability the executives, arrange clog, heterogeneity and association conventions, asset limitation and stage heterogeneity, setting mindfulness, introduction and convenience issues, battery life and vitality mindfulness, and cloud API Security Management. From these surveys, we concluded that the MCC framework is for the most part influenced by the portability. Consequently, proficient systems are required for additional upgrade in group of people yet to come systems.

\section{REFERENCES}

[1] Linthicum, "Connecting Fog and Cloud Computing," in IEEE Cloud Computing, 2017, vol. 4, no. 2, pp. 18- 20.

[2] Linthicum, D.S., "The Technical Case for Mixing Cloud Computing and Manufacturing," in IEEE Cloud Computing, 2016, 3(4), pp.12-15.

[3] Linthicum, D.S., "Cloud Computing Changes Data Integration Forever: What's Needed Right Now," in IEEE Cloud Computing, 2017, 4(3), pp.50-53.

[4] Zhou, B., Dastjerdi, A.V., Calheiros, R.N., Srirama, S.N. and Buyya, R., " mCloud: A context-aware offloading framework for heterogeneous mobile cloud," in IEEE Transactions on Services Computing, 2017, 10(5), pp.797- 810 .

[5] Fowley, F., Pahl, C., Jamshidi, P., Fang, D. and Liu, X., "A classification and comparison framework for cloud service brokerage architectures," in IEEE Transactions on Cloud Computing, 2018, 6(2), pp.358-371.

[6] Shah, S.C., "Recent advances in mobile grid and cloud computing," in Intelligent Automation \& Soft Computing, 2017, pp.1-13.

[7] Fu, J., Jones, M., Liu, T., Hao, W., Yan, Y., Qian, G. and Jan, Y.K., “A novel mobile-cloud system for capturing and analyzing wheelchair maneuvering data: a pilot study," in Assistive Technology, 2016, 28(2), pp.105-114.

[8] Xu, B., Xu, L., Cai, H., Jiang, L., Luo, Y. and Gu, Y.,. "The design of an $\mathrm{m}$-Health monitoring system based on a cloud computing platform," in Enterprise Information Systems, 2017, 11(1), pp.17-36.

[9] Tseng, F.H., Cho, H.H., Chang, K.D., Li, J.C. and Shih, T.K.,. "Application-oriented offloading in heterogeneous networks for mobile cloud computing," in Enterprise Information Systems, 2018, 12(4), pp.398-413.

[10] Morales-Sandoval, M., Vega-Castillo, A.K. and Diaz-Perez, A., "A secure scheme for storage, retrieval, and sharing of digital documents in cloud computing using attribute-based encryption on mobile devices," in Information Security Journal: A Global Perspective, 2014, 23(1-2), pp.22-31.
[11] Singh, R., "Genetic-variable neighborhood search with thread replication for mobile cloud computing," in International Journal of Parallel, Emergent and Distributed Systems, 2017, 32(5), pp.486-501.

[12] Psannis, K.E., Xinogalos, S. and Sifaleras, A.,. "Convergence of Internet of things and mobile cloud computing. Systems Science \& Control Engineering," in Open Access Journal, 2014, 2(1), pp.476-483.

[13] Xu, G., Yu, W., Chen, Z., Zhang, H., Moulema, P., Fu, X. and Lu, C.,. "A cloud computing based system for cyber security management," in International Journal of Parallel, Emergent and Distributed Systems, 2015, 30(1), pp.29-45.

[14] Mamei, M., Roli, A. and Zambonelli, F.,. "Emergence and control of macro-spatial structures in perturbed cellular automata, and implications for pervasive computing systems," in IEEE Transactions on Systems, Man, and Cybernetics-Part A: Systems and Humans, 2005, 35(3), pp.337-348.

[15] Samimi, F.A., McKinley, P.K., Sadjadi, S.M., Tang, C., Shapiro, J.K. and Zhou, Z.,. "Service clouds: distributed infrastructure for adaptive communication services," in IEEE Transactions on Network and Service Management, 2007, 4(2), pp.84-95.

[16] Lin, Y., Shao, L., Zhu, Z., Wang, Q. and Sabhikhi, R.K., "Wireless network cloud: Architecture and system requirements," in IBM Journal of Research and Development, 2016, 54(1), pp.4-1.

[17] Kumar, K. and Lu, Y.H., "Cloud computing for mobile users: Can offloading computation save energy?" in Computer, 2010, 43(4), pp.5156.

[18] Li, Z., Chen, C. and Wang, K., "Cloud computing for agent-based urban transportation systems," in IEEE Intelligent Systems, 2010, 26(1), pp.73-79.

[19] Deboosere, L., Vankeirsbilck, B., Simoens, P., De Turck, F., Dhoedt, B. and Demeester, P., "Cloud-based desktop services for thin clients," in IEEE Internet Computing, 2012, 16(6), pp.60-67.

[20] Ahmed, A., Boulahia, L.M. and Gaiti, D., "Enabling vertical handover decisions in heterogeneous wireless networks: A state-of-the-art and a classification,” in IEEE Communications Surveys \& Tutorials, 2014, 16(2), pp.776-811.

[21] Tian, D., Wei, J., Zhou, J., Sheng, Z., Chen, M., Ni, Q. and Leung, V.C., "From cellular decision making to adaptive handoff in heterogeneous wireless networks," in IEEE Wireless Communications Letters, 2018, 7(1), pp.2-5.

[22] Deb, S. and Monogioudis, P., "Learning-based uplink interference management in 4G LTE cellular systems," in IEEE/ACM Transactions on Networking (TON), 2015, 23(2), pp.398-411.

[23] Wang, F., Wang, Z., Qian, C., Dai, L. and Yang, Z., "Efficient vertical handover scheme for heterogeneous VLC-RF systems," in Journal of Optical Communications and Networking, 2015, 7(12), pp.1172-1180.

[24] Nguyen-Vuong, Q.T., Agoulmine, N., Cherkaoui, E.H. and Toni, L., "Multicriteria optimization of access selection to improve the quality of experience in heterogeneous wireless access networks," in IEEE Transactions on Vehicular Technology, 2013, 62(4), pp.1785-1800.

[25] Mehmeti, F. and Spyropoulos, T., "Performance analysis of mobile data offloading in heterogeneous networks," in IEEE Transactions on Mobile Computing, 2017, 16(2), pp.482-497.

[26] La Corte, A., A. Puliafito, and O. Tomarchio, "QoS management in programmable networks through mobile agents," in Microprocessors and Microsystems, 2001, 25(2): p. 111-120.

[27] Manner, J., et al., "Evaluation of mobility and quality of service interaction," in Computer Networks, 2002, 38(2): p. 137-163.

[28] Aoul, Y.H., et al. "M3G: A mobile multicast multimedia gateway for seamless IPv4/IPv6 transition," in IFIP/IEEE International Conference on Management of Multimedia Networks and Services, 2003, Springer.

[29] Mun, Y. and Y. Kim, "A location management scheme to provide IP mobility over wireless ATM," in Future Generation Computer Systems, 2004, 20(2): p. 205-219.

[30] Kallath, D., "Trust in trusted computing - the end of security as we know it" in Computer Fraud \& Security, 2005, (12): p. 4-7.

[31] De la Oliva, Antonio, Carlos Jesús Bernardos, and María Calderón. "Practical evaluation of a network mobility solution." In EUNICE 2006: 
Networks and Applications Towards a Ubiquitously Connected World. Springer, Boston, MA, 2006, 133-144.

[32] Samimi, Farshad A., et al. "Service clouds: distributed infrastructure for adaptive communication services," in IEEE Transactions on Network and Service Management 4.2, 2007, 84-95.

[33] Harada, Hiroshi, et al. "A software defined cognitive radio system: cognitive wireless cloud," in Global Telecommunications Conference, 2007, GLOBECOM'07, IEEE.

[34] Munasinghe, Kumudu S., and Abbas Jamalipour. "A 3GPP-IMS based approach for converging next generation mobile data networks Communications", in ICC'07. IEEE International Conference on. IEEE, 2007.

[35] Varga, E., et al. "Novel information dissemination solutions in biologically inspired networks Telecommunications," in ConTel 2007. 9th International Conference on. IEEE, 2007.

[36] Xiao, Yunpeng, Yang Tao, and Qian Li. "A new wireless web access mode based on cloud computing," in Computational Intelligence and Industrial Application, 2008. PACIIA'08. Pacific-Asia Workshop on. Vol. 1. IEEE.

[37] Ghassemian, Mona, and Hamid Aghvami. "An investigation of the impact of mobility on the protocol performance in wireless sensor networks," in Communications, 2008 24th Biennial Symposium on. IEEE, 2008.

[38] Ahmad, Syed Zubair, Muhammad Abdul Qadir, and Mohammad Saeed Akbar. "A distributed resource management scheme for load-balanced QoS provisioning in heterogeneous mobile wireless networks," in Proceedings of the 4th ACM symposium on QoS and security for wireless and mobile networks. ACM, 2008.

[39] Boldrini, Chiara, Marco Conti, and Andrea Passarella. "Exploiting users' social relations to forward data in opportunistic networks: The HiBOp solution," in Pervasive and Mobile Computing , 2008, 4.5 (2008): 633-657.

[40] Toor, Yasser, et al. "Vehicle ad hoc networks: Applications and related technical issues," in IEEE communications surveys \& tutorials 10.3, 2008, 74-88.

[41] Shaw, Gareth, and Allan Williams. "Knowledge transfer and management in tourism organisations: An emerging research agenda," in Tourism Management 30.3, 2009, 325-335.

[42] [Kim, Jonghyun, Vinay Sridhara, and Stephan Bohacek. "Realistic mobility simulation of urban mesh networks," in Ad Hoc Networks 7.2, 2009, 411-430.

[43] [Elston, Jack, et al. "Net-centric communication and control for a heterogeneous unmanned aircraft system," in Journal of intelligent and Robotic Systems 56.1-2, 2009, 199-232.

[44] Klein, Andreas, et al. "Access schemes for mobile cloud computing," in Mobile Data Management (MDM), 2010 Eleventh International Conference on. IEEE, 2010.

[45] Liu, Leslie, Randy Moulic, and Dennis Shea. "Cloud service portal for mobile device management," in e- Business Engineering (ICEBE), 2010 IEEE 7th International Conference on. IEEE, 2010.

[46] Satyanarayanan, Mahadev. "Mobile computing: the next decade," in Proceedings of the 1st ACM workshop on mobile cloud computing \& services: social networks and beyond. ACM, 2010.

[47] Huerta-Canepa, Gonzalo, and Dongman Lee. "A virtual cloud computing provider for mobile devices," in Proceedings of the 1st ACM Workshop on Mobile Cloud Computing \& Services: Social Networks and Beyond. ACM, 2010.

[48] Munasinghe, Kumudu S., and Abbas Jamalipour. "An analytical evaluation of mobility management in integrated WLAN-UMTS networks," in Computers \& Electrical Engineering 36.4, 2010, 735-751.

[49] Antoniou, Josephine, et al. "Supporting context-aware multiparty sessions in heterogeneous mobile networks," in Mobile Networks and Applications 15.6, 2010, 831-844.

[50] Armbrust, Michael, et al. "A view of cloud computing," in Communications of the ACM 53.4, 2010, 50-58.
[51] Li, ZhenJiang, Cheng Chen, and Kai Wang. "Cloud computing for agent-based urban transportation systems," in IEEE Intelligent Systems 26.1, 2011, 73-79.

[52] Sardis, Fragkiskos, et al. "On the investigation of cloud-based mobile media environments with service- populating and QoS-aware mechanisms," in IEEE transactions on multimedia 15.4, 2013, 769-777.

[53] Amoroso, Edward G. "From the enterprise perimeter to a mobilityenabled secure cloud," in IEEE Security \& Privacy 11.1 (2013): 23-31, 2013.

[54] Panta, Rajesh K., et al. "Phoenix: Storage using an autonomous mobile infrastructure," in IEEE Transactions on Parallel and Distributed Systems 24.9, 2013, 1863-1873.

[55] Gkatzikis, Lazaros, and Iordanis Koutsopoulos. "Migrate or not? exploiting dynamic task migration in mobile cloud computing systems," in IEEE Wireless Commun. 20.3, 2013, 1-0.

[56] Taleb, Tarik, Konstantinos Samdanis, and Adlen Ksentini. "Supporting highly mobile users in cost-effective decentralized mobile operator networks," in IEEE Transactions on Vehicular Technology 63.7, 2014, 3381-3396.

[57] Zhang, Daqiang, et al. "Mobility prediction in telecom cloud using mobile calls," in IEEE Wireless Communications 21.1, 2014, 26-32.

[58] Qi, Qi, Jianxin Liao, and Yufei Cao. "Cloud service-aware location update in mobile cloud computing," in IET Communications 8.8, 2014, 1417-1424.

[59] Chen, Shanzhi, et al. "Mobility-driven networks (MDN): from evolution to visions of mobility management," in IEEE Network 28.4,2014, 66-73.

[60] Yue, Hao, et al. "DataClouds: Enabling community-based data-centric services over the Internet of Things," in IEEE Internet of Things Journal $1.5,2014,472-482$.

[61] $\mathrm{Li}$, Wenzhong, et al. "Mechanisms and challenges on mobilityaugmented service provisioning for mobile cloud computing," in IEEE Communications Magazine 53.3, 2015, 89-97.

[62] Aissioui, Abdelkader, et al. "Toward Elastic Distributed SDN/NFV Controller for 5G Mobile Cloud Management Systems," in IEEE Access 3.0, 2015, 2055-2064.

[63] Rahimi, M. Reza, et al. "On optimal and fair service allocation in mobile cloud computing," in IEEE Transactions on Cloud Computing 2015.

[64] Kumar, Neeraj, Sherali Zeadally, and Joel JPC Rodrigues. "Vehicular delay-tolerant networks for smart grid data management using mobile edge computing," in IEEE Communications Magazine 54.10, 2016, 6066.

[65] Ha, Minkeun, Seong Hoon Kim, and Daeyoung Kim. "Intra-MARIO: A Fast Mobility Management Protocol for 6LoWPAN," in IEEE Transactions on Mobile Computing 16.1, 2017, 172-184.

[66] Ha, Minkeun, Seong Hoon Kim, and Daeyoung Kim. "Intra-MARIO: A Fast Mobility Management Protocol for 6LoWPAN," in IEEE Transactions on Mobile Computing 16.1, 2017, 172-184.

[67] Jeon, Seil, et al. "Distributed Mobility Management for the Future Mobile Networks: A Comprehensive Analysis of Key Design Options," in IEEE Access 5, 2017, 11423-11436.

[68] Ahmad, Awais, et al. "Energy efficient hierarchical resource management for mobile cloud computing," in IEEE Transactions on Sustainable Computing 2.2, 2017, 100-112.

[69] Chaudhary, Rajat, Neeraj Kumar, and Sherali Zeadally. "Network service chaining in fog and cloud computing for the $5 \mathrm{G}$ environment: Data management and security challenges," in IEEE Communications Magazine 55.11, 2017, 114-122.

[70] Enayet, Asma, et al. "A mobility-aware optimal resource allocation architecture for big data task execution on mobile cloud in smart cities," in IEEE Communications Magazine 56.2, 2018, 110-117.

[71] A. Aissioui, A. Ksentini, A. Gueroui and T. Taleb, "Toward Elastic Distributed SDN/NFV Controller for 5G Mobile Cloud Management Systems", IEEE Access, vol. 3, pp. 2055-2064, 2015.

[72] L. Pallavi, A. Jagan, B. Thirumala Rao, "ERMO2 algorithm: an energy efficient mobility management in mobile cloud computing system for 5G heterogeneous networks", IJECE, vol. 9, 2019. 